Emil Salim*

\title{
Senseless Pain in the Phenomenology of Religious Experience
}

https://doi.org/10.1515/opth-2020-0105

received April 08, 2020; accepted July 27, 2020

\begin{abstract}
There are three models of pain in the phenomenology of religious experience. The first model suggests that pain is instrumental to attaining the desired religious experience. The second model proposes that pain is constitutive of the desired religious experience. The third model, which is a model of senseless pain in religious experience, is underdeveloped. I provide an exposition of this model in this article. I also give four arguments for the necessity of affirming senseless pain in the phenomenology of religious experience. First, affirming senseless pain in religious experience provides a way to describe the process of purpose attribution to pain qua a sensation or a feeling. Second, such an affirmation also provides a way for describing the meaning formation in religious experience through interpreting pain qua symbol. Third, the affirmation is also necessary to maintain continuity between mundane and religious experiences. There are instances of senseless pain in the literature on tragedy, chronic pain, and torture. Maintaining continuity between ordinary and religious experiences via the notion of senseless pain opens the possibility of developing mysticism in everyday life. Lastly, the presence of the unknown in senseless pain makes room for mystery in religious experience.
\end{abstract}

Keywords: pain, purpose attribution, instrumental model, constitutive model, symbol, sensation, feeling, mystery

There are three models of pain in the phenomenology of religious experience, viz., the instrumental model, the constitutive model, and the senseless model of pain. The first two models are well discussed in the literature on religion but not the third model. In this article, I first discuss these three models of pain in the phenomenology of religious experience (Section 1). I will then give four arguments for why it is important to affirm the existence of senseless pain, which is the third model, in the phenomenology of religious experience (Section 2). In Section 3, I anticipate some objections and give a rejoinder to them before ending the article with a conclusion (Section 4).

\section{Three models of pain in religious experience}

The properties of religious experience are usually described in terms that are considered desirable. McNamara lists seventeen common features of religious experience, including a deeply felt positive mood, a sense of sacredness, euphoria, and an encounter with God. ${ }^{1}$ How does pain play a role in the

1 McNamara, The Neuroscience of Religious Experience, 15-6.

\footnotetext{
* Corresponding author: Emil Salim, Sekolah Tinggi Teologi Reformed Indonesia, Jakarta, Indonesia, e-mail: emil.salim@reformedindonesia.ac.id ORCID: Emil Salim 0000-0002-1390-8566
} 
phenomenology of religious experience? The current literature on religious experience offers us three models of pain. ${ }^{2}$

\subsection{The instrumental and the constitutive models of pain}

The first model is that of pain as an instrument used to achieve a desired religious experience. In his article, "Pain and Ecstatic Religious Experience," Ariel Glucklich argues that pain has instrumental value in helping one achieve a higher form of pleasure or bliss in religious experience. ${ }^{3}$ In another work, he gives an example of how pain in the Native Spirituality Sun Dance enhances one's religious experience: "There is no question that without the pain of the pierced chest [Manny Twofeathers] would not have had [the emotions of sorrow, love, compassion, dependence, fear, shame, courage, happiness, and exultation] surface and would not have experienced them so profoundly." ${ }^{4}$ In the same spirit, Flynn contends that, for the Spanish mystics, pain is instrumentally significant in the purification of the soul and the achievement of a more desired ecstasy. ${ }^{5}$ To give another example, in her discussion of Mechthild of Magdeburg, McGowin concludes that, for the medieval women mystics, "the pursuit and embrace of physical pain became a focal point of their ascetic religious devotion and the primary means by which they experienced union with God." Lastly, MacKendrick's discussion of asceticism comes to the conclusion that "ostensibly, the saint strives through asceticism to break her will and pride, to engender humility."7 For the saint, pain is instrumental to developing a better character. ${ }^{8}$

Although seeing pain as instrumentally valuable enables one to capture many religious phenomena in mysticism, it is not the only way pain is described in religious experiences. The second model of pain that has appeared in the literature on religious experience describes pain as constitutive of the desired religious experience itself. Vloebergs discusses the phenomenon of stigmata and points out that for some mystics, "the pain experience is the only locus where they encounter God. Pain is the locus theologicus." In his exposition of St. Teresa of Avila, Steinbock points out that for St. Teresa, pain can "arise from one's intimate depths, which is experienced as a longing for God." ${ }^{10}$ MacKendrick identifies this second model as well in her discussions of Bataille, Catherine of Siena, and Angela of Foligno. She suggests that there is continuity between pleasure and pain and argues that "pain practices are also practices of a kind of joy, a self-exceeding joy that is inherently both religious (in its effort to transcend selfhood) and paradoxical." 11 Louchakova-Schwartz has argued forcefully for the possibility of a transmutation of religious emotions, where one emotion (e.g., anger, hatred) is not replaced by another but teleologically and qualitatively

\footnotetext{
2 The models of pain in this article are orthogonal to the models of pain discussed by Glucklich, Sacred Pain, 16-30.

3 Glucklich, "Pain and Ecstatic Religious Experience."

4 Glucklich, Sacred Pain, 149.

5 Flynn, "The Spiritual Uses of Pain in Spanish Mysticism."

6 McGowin, "Eroticism and Pain in Mechthild of Magdeburg's The Flowing Light," 620.

7 MacKendrick, Counterpleasures, 79. The intuition that pain can be instrumental to a positive life experience is robust in that it goes beyond the domain of religion. The sociological analysis of pain shows that embracing pain can be instrumental in strengthening communities and religious commitment by signifying desirable communal values such as loyalty and courage. See Shilling and Mellor, "Saved From Pain or Saved Through Pain?," 530. In the world of arts, Marina Abramović sees pain as a "door to cross into another state of consciousness." Pain is only an instrument to achieve an ulterior end in the performing arts. Yu-Chien Wu, an interpreter of Abramović, argues that the experience of pain is not the main focus of Abramović's messages but rather the acts themselves, such as the cuts and burns that Abramović would endure to convey meaning. See Wu, "Who is in Pain?"

8 The instrumental view of pain is also present in Jewish (see Levinson, "Pain and Suffering"), Hindu (see Pandya, "Hindu Philosophy on Pain”), and Islamic theologies (see Al-Jeilani, "Pain”).

9 Vloebergs, "Wounding Love," 20.

10 Steinbock, Phenomenology and Mysticism, 63.

11 MacKendrick, "Not Enough: Ascetic Excess and the Quantity of Pleasure."
} 
transformed into a more pleasing state (e.g., into compassion and ecstasy) by means of meditative practices, especially in the Neo-Buddhist tradition..$^{12}$ Such a transformation might provide a mechanism for explaining the continuity of pain and pleasure in religious experience. The second model can also be expressed in a way to depict the Christian self as a sufferer, that is, to be Christian is to suffer just like the saints do. ${ }^{13}$ Kitamori similarly believes that human pain is a service to the pain of God who has loved the unlovable and let his son die to save the world. ${ }^{14}$ These two models of pain, viz., pain as an instrument to achieve a desired religious experience and pain as constitutive of the desired religious experience, are easier to accommodate into one's notion of religious experience as pain can somehow be seen as having positive value.

\subsection{Senseless pain}

In his analyses of the book of Job, Dahl has recognized a third model of pain in the phenomenology of religious experience, viz., pain as senseless or meaningless. ${ }^{15}$ However, he still tries to find instrumental value in Job's bodily pain. He concludes that physical pain would remind Job that he is embodied. ${ }^{16}$

This kind of explanation is questionable for the reason that one only needs a needle prick as a reminder of her embodiment. The intensity of Job's pain seems unnecessary if pain only serves as a reminder. Also, physical pleasure would do as well to remind one that she is embodied. In Ideas II, Husserl has asserted that both pleasure and pain, as sensing, would have an immediate bodily localization. ${ }^{17}$ Job must indeed endure pain in his life as a religious person. Nevertheless, it is far from obvious that the excruciating pain he endures has any instrumental use in his spirituality. Oftentimes, pain is described as senseless, devoid of any instrumental value in attaining a desired religious experience, and it is sometimes not considered an integral part of the religious experience. It is important to recognize that senseless pain has a place in religious experience.

Studies on the phenomenology of pain have recognized the existence of senseless pain. Grüny, for example, suggests that meaningful and meaningless pains may be interwoven and weaved into life experiences, including in situations of torture. ${ }^{18}$ In the same way, Morris affirms that "pain [...] spends its existence moving in-between extremes of absolute meaninglessness and full meaning." ${ }^{19}$ Yet no elaborate discussion has been provided for the importance of senseless pain in religious experience. In what follows, I would like to do just that.

As a working definition, pain can be considered senseless in the phenomenology of religious experience if and only if it doesn't have an instrumental or constitutive function in realizing a desired religious experience before, during, and after it is experienced. In other words, the sufferer of pain either does not or cannot attribute purpose to it in a religious context. Accordingly, in this article, senseless pain is not senseless or meaningless tout court but only teleologically so. In other words, pain is senseless when it is devoid of purpose. In a Wittgensteinian vein, we can certainly say, "I am in senseless pain." Teleologically senseless pain does not have to be seen as absurd or enigmatic, but it can be treated as such. It is important to note, however, that this teleological senselessness does not have to be permanent. In fact, people often try to attribute purpose to teleologically senseless pain, hence transforming it into something else.

12 Louchakova-Schwartz, "The Emancipatory Continuity of Religious Emotion," 85.

13 Perkins, The Suffering Self, 205.

14 Kitamori, Theology of the Pain of God, 90.

15 See Dahl, "Job and the Problem of Physical Pain," 52; Dahl, The Problem of Job and the Problem of Evil, 31.

16 Dahl, "Job and the Problem of Physical Pain," 53-4.

17 Husserl, Ideas Pertaining to a Pure Phenomenology and to a Phenomenological Philosophy, 172.

18 Grüny, "Zwischen Aspirin und Algodizee," 20.

19 Morris, The Culture of Pain, 35. 
With the recognition of the existence of teleologically senseless pain, we can distinguish between some pains that are teleologically senseless and others to which a purpose has been attributed. This stratification of pain matches both nonreligious and religious experiences in which after an instance of pain, people often try to make sense of it by figuring out its cause, extent, and significance. Leder calls such a strategy "the hermeneutical moment." ${ }^{20}$ Morris also acknowledges that we need a hermeneutics of pain, given that we often give meaning to otherwise meaningless pain. ${ }^{21}$

Senseless pain qua teleologically senseless indeed does not have a purpose, but surely one can use it to construct a narrative. Sigurdson writes on the possibility of narrating pain, saying that "pain or misfortunes can indeed be lonely and alienating events or states, but through narrating them it is possible to re-establish a relation to one's significant others." 22 In an anthropological study of chronic illnesses, Garro finds that people construct a narrative to explain the genesis, meaning, and treatment of chronic pain. Despite the construction of such a narrative, it is still possible that chronic pain itself is considered teleologically senseless. One patient in the study was recorded saying, “I can't help but feel like [...] not that there's a purpose to my pain, but that I haven't let it triumph. I've made it into something else. I've made it into a way to make connections to people."23

One can also overcome teleological senselessness in the way Tillich tells us to be courageous in life. This attitude involves a self-affirmation despite the meaninglessness, loneliness, and emptiness of life. Tillich also advocates for a biological self-affirmation, which is a courageous attitude in the face of physical difficulties, including pain. ${ }^{24}$ Senseless pain that has been overcome by courage, however, does not necessarily lose its teleological senselessness.

The exposition of teleologically senseless pain ends here. In Section 2, I argue that the recognition of teleologically senseless pain in the phenomenology of religious experience enables us to describe the phenomenology of religious experience in a way that is not provided for by the instrumental and constitutive models of pain.

\section{The explanatory power of senseless pain}

In describing the phenomenology of religious experience, it is necessary to acknowledge the presence of teleologically senseless pain. I provide four arguments for why that is so.

\subsection{Pain as a sensation or a feeling}

To begin with, there is a trivial understanding of pain as something teleologically senseless if we remember that pain can be understood as a sensation that is not necessarily attached to any purpose, just like hotness or hardness. Among philosophers, for example, it is common to discuss whether pain is identical to the firing of C-fibers, which are nerve endings whose stimulation was thought to be the neural activity responsible for the experience of pain..$^{25}$ In his book on conscious living and conscious dying, as another example, Stephen Levine suggests that when one practices mindfulness and investigates the experience of pain beyond the concepts of pain, the pain may dissolve into multiple changing sensations such as heat, tingling, or pressure. ${ }^{26}$ What is important to recognize is that some physical pains have a

20 Leder, The Absent Body, 78.

21 Morris, The Culture of Pain, 33.

22 Sigurdson, "Only Vulnerable Creatures Suffer," 98.

23 Garro, "Chronic Illness and the Construction of Narratives," 130.

24 Tillich, The Courage to Be, 78.

25 Grahek, Feeling Pain and Being in Pain, 141.

26 Levine, Who Dies?, 114. 
biological cause. That causal explanation can serve as an identification that pain is some kind of a physical sensation.

It is crucial to note that in the literature on the phenomenology of pain, there is a question about whether pain is a sensation or a feeling. William James says that pain is a sensation, although when it comes to nomenclature, he ponders about whether pain can also be named a feeling. ${ }^{27}$ Brentano, by contrast, suggests that although pain is often mistakenly termed a sensation, pain must be an intentional feeling and not a nonintentional sensation. ${ }^{28} \mathrm{~A}$ needle prick, for instance, involves a sensation, but the pain from the needle prick is an intentional mental state that presents a sensory quality of being stuck by the needle. ${ }^{29}$ Brentano sees that the experience of pain (and pleasure) presents sui generis "algedonic" qualities that are different from other sensory qualities such as color and sound. ${ }^{30}$ While James believes that pain is a sensation and Brentano thinks that pain is a feeling, Husserl suggests that pain can be a simple "feeling-sensation" and also an intentional feeling. ${ }^{31}$ For Husserl, pain has a dual nature: it is a simple sensation that one can transform into a more complex intentional feeling by conceptualizing it as an experience of localized pain, such as the pain of being burned..$^{32}$ Looking at these thinkers, it is clear that there is more than one way to describe what pain is. However, whichever view of the nature of pain is adopted, whether it is a sensation (James), a feeling (Brentano), or both (Husserl), these descriptions of pain are not automatically attached to the notion of purpose in religious experience. ${ }^{33}$

Affirming that teleologically senseless pain exists in the phenomenology of religious experience is especially beneficial in the initial phase of the experience of pain, before one is able to attribute purpose to it. After experiencing pain either as a sensation or as a feeling, one can transform this teleologically senseless pain into something more meaningful and incorporate this transformed pain into the description of one's phenomenology of religious experience. This strategy is often/sometimes used by people trying to make sense of pain. Allport, in his preface to Frankl's Man's Search for Meaning, for example, points out that the will to live among the Holocaust prisoners is realized when they are able to make sense of their "apparently senseless suffering." ${ }^{4}$ In her discussion of Plato's Republic, Nussbaum also insists that "we must be made conscious of our pain [of the empirical life] before we can be brought up to a point at which we are ready to pursue a way of life that involves giving up, or radically revising, much that we now value." ${ }^{35}$ Lastly, Scheler has suggested that one can see pain and suffering through the lens of sacrifice, as is done in Christianity. ${ }^{36}$ Affirming teleologically senseless pain in religious experience makes it possible

27 James, The Principles of Psychology, 185; James, The Principles of Psychology, 1.

28 Brentano, Psychology from an Empirical Standpoint, 87.

29 Massin, "Brentano on Sensations and Sensory Qualities," 95.

30 Kriegel, Brentano's Philosophical System, 53.

31 Husserl, Logical Investigations, 110. A similar distinction is identified by C. S. Lewis who proposes that pain can be recognized simply as a sensation, e.g., a faint ache in one's limbs, but also as a more complex experience that involves like or dislike. See Lewis, The Problem of Pain, 87.

32 See Hardcastle, “A Brief and Potted Overview on the Philosophical Theories of Pain,” 22. There is a debate about whether or not pain is intentional, i.e., whether pain is about something. Geniusas stratifies pain and argues that humans experience both intentional and nonintentional pains in different stages of their experience. See Geniusas, "Pain and Intentionality." We do not need to side with Brentano (for the view of intentional pain) or anyone else offering an alternative idea. It is worth noting, however, that nonintentional pain seems to be compatible with the trivial notion of teleologically senseless pain in that the experienced pain is not about anything in particular. However, one can still talk about teleologically senseless pain even with the view that pain is intentional. Pain can have an object, cause, or direction but still be deprived of purpose.

33 There is also a distinction between sensation and perception. James, for instance, thinks that the function of sensation is of mere acquaintance with a fact, whereas the function of perception is knowledge about a fact. See James, The Principles of Psychology, 1-2. Another distinction can be made between feeling and emotion. For example, Brentano seems to think that pain is a feeling if there is an immediacy (here and now) in the presentation of a bad quality, whereas pain as a negative emotion doesn't have such immediacy. See Kriegel, Brentano's Philosophical System, 211. My analysis of the teleological senselessness of pain also applies to the descriptions of pain as perception or emotion and that these descriptions do not entail the idea of purpose in religious experience.

34 See the preface to Frankl, Man's Search for Meaning.

35 Nussbaum, The Fragility of Goodness, 163.

36 Scheler, On Feeling, Knowing, and Valuing, 87. 
for people to describe the phenomenology of religious experience in a way that includes attribution of purpose.

\subsection{Pain as a symbol}

Another reason why senseless pain should be incorporated into the phenomenology of religious experience is that religious experience consists of symbols that are ready to be interpreted, as is clearly seen in the performance of rituals. Insofar as it is a part of one's religious experience, pain should also be considered a symbol to be interpreted. McNamara, for example, quotes Borges's statement that "everything is a symbol, even the most piercing pain." ${ }^{37}$ The idea of pain as a symbol is apparent in the phenomenon of stigmata. In Victorian England, stigmata was interpreted in many ways, including as a form of fraud or crime, a disease, and a social disturbance to the transition out of the premodern era. Despite the diversity of interpretations, it is clear that stigmata is considered a representation or a symbol available "to be decoded, interpreted and appropriated." 38

It is true that pain can be seen as a symbol even in the instrumental and the constitutive models. Nevertheless, the symbolic nature of pain is manifested completely in senseless pain that has not been embedded into instrumental or religious narratives. In a way, the attribution of purpose to teleologically senseless pain can be seen as a Kantian move of refusing to describe the noumenal. Such an attribution, by contrast, can be described as a form of post facto justification of what is happening in one's life, which in turn can constitute the phenomenology of one's religious experience. Acknowledging the existence of teleologically senseless pain enables one to describe the phenomenology of religious experience in a way that contains meaning formation, but here, through the interpretation of pain as a symbol. Teleologically senseless pain may thus not be an immediate context for one to encounter God but rather an occasion to have a religious experience through the imposition of meaning, i.e., through the attribution of purpose, to pain.

\subsection{Continuity with nonreligious experiences}

My third argument for the necessity of accommodating teleologically senseless pain in the phenomenology of religious experience is that there should be a way for the phenomenology of religious experience to incorporate nonreligious experiences. Brother Lawrence, for example, talks about picking up a straw from the ground as part of his love for God. ${ }^{39}$ Mundane experience can be something like a purposeless irritant that could be transformed into a pearl of religious experience.

In nonreligious experiences, three cases of teleologically senseless pain are found in the instances of torture, chronic pain, and tragedy. Something like teleologically senseless pain is discussed by Scarry in her exposition of torture. The intensity of pain in torture destroys a person's self and world. This brutality is senseless, and it deprives the experience of any purpose. ${ }^{40}$ The experience of chronic pain may also bring a phenomenology of senselessness. Wendell writes, "With chronic pain, I must remind myself over and over again that the pain is meaningless, that there is nothing to fear or resist, that resistance only creates tension, which makes it worse." ${ }^{41}$

37 McNamara, The Neuroscience of Religious Experience, 191.

38 Smeyers, "Making Sense of Stigmata," 239.

39 Lawrence, The Practice of the Presence of God, 98.

40 Scarry, The Body in Pain, 34-5.

41 Wendell, The Rejected Body. 
Tragic pain such as that depicted in Shakepeare's Lear can be put in a social context in which pain can be expressed by the sufferer and recognized by others (both the characters in the tragedy and the audience). Rowan Williams writes that "Tragedy typically displays the agonizing isolation of the person in pain, but, in the very fact of displaying it to an audience and within the conversation of the drama, the dramatist displays suffering as something that can be spoken of, and even to." ${ }^{42}$ It is unclear, however, whether expressed or recognized pain has purpose for the tragic characters themselves. Thompson cites the example of Ivan Ilyich who is puzzled by a gnawing pain that is relentless and somehow teleologically senseless. ${ }^{43}$ While tragic pain may bring some meaning to bystanders, tragic pain seems to be purposeless for the sufferers.

Despite the senselessness of torture, chronic pain, and tragic pain, they can be included in the phenomenology of religious experience. For instance, although teleologically senseless pain itself is not given any purpose, it can result in a philosophical or spiritual understanding, such as a deeper realization of human weaknesses in the face of external control or one's mortality, the brutality of evil, and the nature of luck and misfortune. The pain itself is left teleologically senseless, but other aspects of the religious experience, including one's encounter with God, can be enriched by its presence.

With the presence of teleologically senseless pain in the phenomenology of religious experience, one can maintain a sense of continuity between nonreligious and religious experiences. Religious experience thus becomes something that is not esoteric or disconnected from daily life or from the so-called "everyday." 44 This continuity is important for the possibility of developing mysticism in everyday life, in which, in Rahner's words, "the ordinary is the most extraordinary." 45

\subsection{Making room for mystery}

Lastly, one should make room for mystery in the phenomenology of religious experience. The instrumental and constitutive models of pain tend to rationalize the experience of pain by giving it some religious purpose, but this would discount the phenomenology of mystery in religious experience.

The presence of teleologically senseless pain, by contrast, would provide an element of mystery or puzzlement in the phenomenology of religious experience. Morris insists that we need to emphasize the mysteriousness of pain, given the fact that much is still unknown about the cause of pain, especially chronic pain. ${ }^{46}$ If the cause of pain is unknown, its treatment and significance might be unknown as well.

We can also argue that we are sometimes unable to attribute purpose to pain even when it is already placed in the context of the phenomenology of religious experience. In the Hebrew Bible, Job cannot find an answer for why he must suffer the pain he has experienced, yet he keeps his faith in God who mysteriously allows such horrendous experiences to occur in his life. The story of Job interpreted as an experience of teleologically senseless pain serves as a "spiritual safety net" for people who might experience something similar and are wondering whether they can still hold on to their faith.

\section{Objections and replies}

One objection to the model of teleologically senseless pain in religious experience is that it may diminish the role of God in life. The objection goes that if God exists, every single event in our lives should have

42 Williams, The Tragic Imagination, 47.

43 Thompson, Waking, Dreaming, Being, 315.

44 Dahl, The Phenomenology and the Holy.

45 Rahner, The Mystical Way in Everyday Life, 64.

46 Morris, The Culture of Pain, 22. 
some kind of purpose. In reply to this objection, we can agree that from God's point of view, it is possible that every pain has a purpose. But in human phenomenology, it is not always possible to attribute purpose to these instances of pain.

Another objection to teleologically senseless pain in religious experience would be the idea that teleologically senseless pain would be deleterious to one's ability to cope with pain. But this objection seems to be based on an empirical question. ${ }^{47}$ If we compare those who think that life is absurd and those who think that it is not, it is not clear which group would better cope with pain. One needs to remember, too, that the ability to cope with pain is a function of many factors, including one's physical and psychological built.

Yet another objection might be that embracing the phenomenology of teleologically senseless pain would diminish one's desire to remove pain from one's life. Either physically, as in the case of chronic pain, or socially, such as in the case of refugees or persecuted minorities, this indifference toward alleviating pain would be undesirable. The response to this objection is threefold. First, it is possible to think of pain, as an undesirable sensation or a feeling, as something inherently bad that should be removed regardless of whether it has a purpose. Second, Marx has argued that giving purpose to pain and suffering might make people think that pain or suffering is acceptable instead of something to be removed. It might thus be argued that if pain has no purpose, people would want to alleviate it sooner. Third, again, whether people would actually want to remove pain if they consider it teleologically senseless is an empirical question. Empirical research needs to be done on whether the attribution of purpose has a positive correlation with the desire to diminish pain.

\section{Conclusion}

This article is a discussion on senseless pain in the phenomenology of religious experience. Senseless pain is deprived of purpose before, during, and after it is being experienced. I have argued that affirming the existence of teleologically senseless pain in the phenomenology of religious experience should be done for four reasons. First, this kind of affirmation is compatible with the trivial understanding of pain as a sensation or a feeling. This understanding gives way for attribution of purpose to pain in one's religious experience. Second, it is compatible with the idea that pain is a symbol that can be interpreted in one's phenomenology of religious experience. Third, it reaffirms the continuity between nonreligious and religious experiences. Lastly, it preserves the sense of mystery in religious experience. It is quite obvious that interdisciplinary studies on senseless pain from various fields such as psychology, anthropology, sociology, philosophy, and theology would enrich the effort to better capture the phenomenology of religious experience..$^{48}$

47 There is indeed an fMRI study that shows that religious people might be able to modulate pain better when they are in a certain religious context. See Wiech et al., "An fMRI Study Measuring Analgesia Enhanced by Religion As a Belief System.” In the study, religious people who are presented with a religious image ("Vergine Annunciate" by Sassoferrator) cope with painful stimulation better than when they are presented with a nonreligious image. Their agnostic or atheist counterparts' modulation of pain, however, is indifferent to the presentation of both religious and nonreligious images. But this kind of study is still very rare. It is hard to gauge whether such a study is pertinent to our discussion of senseless pain.

48 My thanks goes to Espen Dahl, Philip Park, the participants of the 2019 Regional Conference of the Society for the Phenomenology of Religious Experience, and the anonymous reviewers of this journal for commenting on an earlier draft of this article. 


\section{References}

Al-Jeilani, Mohamed. "Pain: Points of View of Islamic Theology.” Acta Neurochirurgica Supplementum 38 (1987), $132-5$. Brentano, Franz. Psychology from an Empirical Standpoint. Translated from the German by Oskar Kraus. New York: Routledge, 2015.

Dahl, Espen. "Job and the Problem of Physical Pain: A Phenomenological Reading.” Modern Theology 32:1 (2016), 45-59. doi: $10.1111 /$ moth.12221.

Dahl, Espen. The Phenomenology and the Holy: Religious Experience after Husserl. Veritas. London: SCM Press, 2010.

Dahl, Espen. The Problem of Job and the Problem of Evil. Cambridge: Cambridge University Press, 2019.

Flynn, Maureen. "The Spiritual Uses of Pain in Spanish Mysticism." Journal of the American Academy of Religion 64:2 (1996), 257-78.

Frankl, Victor E. Man's Search for Meaning. New York: Pocket Books, 1984.

Garro, Linda C. "Chronic Illness and the Construction of Narratives." In Pain as Human Experience: An Anthropological Perspective, edited by Mary-Jo DelVecchio Good, Paul E. Brodwin, Byron J. Good, and Arthur Kleinman, 100-137. Comparative Studies of Health Systems and Medical Care. Berkeley: University of California Press, 1992.

Geniusas, Saulius. "Pain and Intentionality." In Perception, Affectivity, and Volition in Husserl's Phenomenology, edited by Roberto Walton, Shigeru Taguchi, Roberto Rubio, 113-33. Phaenomenologica 222. Cham, Switzerland: Springer, 2017.

Glucklich, Ariel. "Pain and Ecstatic Religious Experience.” Oxford Handbooks Online. https://doi.org/10.1093/oxfordhb/ 9780199935420.013.38. https://www.oxfordhandbooks.com/view/10.1093/oxfordhb/9780199935420.001.0001/ oxfordhb-9780199935420-e38?print.

Glucklich, Ariel. Sacred Pain: Hurting the Body for the Sake of the Soul. Oxford: Oxford University Press, 2001. Grahek, Nikola. Feeling Pain and Being in Pain, 2nd ed. Cambridge: Massachusetts Institute of Technology, 2007.

Grüny, Christian. "Zwischen Aspirin und Algodizee: zum Problemfeld Schmerz und Sinn." Psychologie und Gesellschaftskritik 33:3 (2009), 7-32.

Hardcastle, Valerie Gray. "A Brief and Potted Overview on the Philosophical Theories of Pain.” In The Routledge Handbook of Philosophy of Pain, edited by Jennifer Corns, 19-28. New York: Routledge, 2017.

Husserl, Edmund. Ideas Pertaining to a Pure Phenomenology and to a Phenomenological Philosophy: Second Book: Studies in the Phenomenology of Constitution. Translated from the German by Richard Rojcewicz and André Schuwer. Collected Works. Dordrecht: Kluwer Academic Publishers, 1989.

Husserl, Edmund. Logical Investigations, edited by Dermot Moran. Translated from the German by J. N. Findlay. Vol. 2. International Library of Philosophy. New York: Routledge, 2001.

James, William. The Principles of Psychology. Vol. 1. Mineola, NY: Dover, 1918.

James, William. The Principles of Psychology. Vol. 2. Mineola, NY: Dover, 1918.

Kitamori, Kazoh. Theology of the Pain of God. Richmond, VA: John Knox Press, 1965.

Kriegel, Uriah. Brentano's Philosophical System: Mind, Being, Value. Oxford: Oxford University Press, 2018.

Lawrence, Brother. The Practice of the Presence of God. Peabody, MA: Hendrickson, 2004.

Leder, Drew. The Absent Body. Chicago: The University of Chicago Press, 1990.

Levine, Stephen. Who Dies? An Investigation of Conscious Living and Conscious Dying. New York: Anchor Books, 1982.

Levinson, N. Peter. "Pain and Suffering: Views of Jewish Theology." Acta Neurochirurgica Supplementum 38 (1987), 129-31.

Lewis, C. S. The Problem of Pain. New York: HarperOne, 1996.

Louchakova-Schwartz, Olga. "The Emancipatory Continuity of Religious Emotion." In The Problem of Religious Experience, edited by Olga Louchakova-Schwartz, 77-99. Contributions to Phenomenology 103. Cham, Switzerland: Springer Nature, 2019. doi: 10.1007/978-3-030-21575-0\5.

MacKendrick, Karmen. Counterpleasures. Albany, NY: State University of New York Press, 1999.

MacKendrick, Karmen. “Not Enough: Ascetic Excess and the Quantity of Pleasure.” Magistra 11:1 (2005), 26. https://search-proquest-com.proxy2.library.illinois.edu/docview/216919225?accountid=14553.

Massin, Olivier. "Brentano on Sensations and Sensory Qualities." In The Routledge Handbook of Franz Brentano and the Brentano School, edited by Uriah Kriegel, 87-100. Routledge Research in Phenomenology. New York: Routledge, 2017.

McGowin, Emily Hunter. “Eroticism and Pain in Mechthild of Magdeburg's The Flowing Light." New Blackfriars 92:1041 (2011), 607-22. doi: 10.1111/j.17412005.2010.01392.x.

McNamara, Patrick. The Neuroscience of Religious Experience. Cambridge: Cambridge University Press, 2009.

Morris, David B. The Culture of Pain. Berkeley: University of California Press, 1991.

Nussbaum, Martha. The Fragility of Goodness: Luck and Ethics in Greek Tragedy and Philosophy. Cambridge: Cambridge University Press, 1986.

Pandya, Sunil K. "Hindu Philosophy on Pain: An Outline.” Acta Neurochirurgica Supplementum 38 (1987), 136-46.

Perkins, Judith. The Suffering Self: Pain and Narrative Representation in the Early Christian Era. London: Routledge, 1995.

Rahner, Karl. The Mystical Way in Everyday Life: Sermons, Prayers, and Essays. Edited and translated by Annemarie S. Kidder. Maryknoll, NY: Orbis Books, 2010.

Scarry, Elaine. The Body in Pain: The Making and Unmaking of the World. Oxford: Oxford University Press, 1985. 
Scheler, Max. On Feeling, Knowing, and Valuing: Selected Writings, edited by Harold J. Bershady. Chicago: The University of Chicago Press, 1992.

Shilling, Chris, and Mellor, Philip A. "Saved From Pain or Saved Through Pain? Modernity, Instrumentalization and the Religious Use of Pain as a Body Technique." European Journal of Social Theory 13:4 (2010), 521-537. doi: $10.1177 / 13684310 / 10382763$.

Sigurdson, Ola. "Only Vulnerable Creatures Suffer: On Suffering, Embodiment and Existential Health." In Phenomenology of the Broken Body, edited by Espen Dahl, Cassandra Falke, Thor Eirik Eriksen, 87-100. Routledge Research in Phenomenology. New York: Routledge, 2019.

Smeyers, Kristof. "Making Sense of Stigmata: How Victorians Explained the Wounds of Christ." Journal of Victorian Culture 24:2 (2019), 227-40. doi: 10. 1093/jvcult/vyc071.

Steinbock, Anthony J. Phenomenology and Mysticism: The Verticality of Religious Experience. Bloomington: Indiana University Press, 2007.

Thompson, Evan. Waking, Dreaming, Being: Self and Consciousness in Neuroscience, Meditation, and Philosophy. New York: Columbia University Press, 2015.

Tillich, Paul. The Courage to Be. 2nd ed. New Haven: Yale University Press, 2000.

Vloebergs, Sander. “Wounding Love: A Mystical-Theological Exploration of Stigmatization." International Journal of Philosophy and Theology 77:1-2 (2016), 1-29. doi: 10.1080/21692327.2016.1199968.

Wendell, Susan. The Rejected Body: Feminist Philosophical Reflections on Disability. New York: Routledge, 1996.

Wiech, Katja, Farias, Miguel, Kahane, Guy, Shackel, Nicholas, Tiede, Wiebke, and Tracey, Irene. "An fMRI Study Measuring Analgesia Enhanced by Religion As a Belief System.” Pain 139:2 (2008), 467-76.

Williams, Rowan. The Tragic Imagination. The Literary Agenda. Oxford: Oxford University Press, 2016.

Wu, Yu-Chien. "Who is in Pain? The Transforming of Symbol in Performances of Marina Abramović." Performance Research 14:4 (2009), 69-73. 